\title{
Molecular Phylogenetic Analyses of Verticillium fungicola and Related Species Causing Dry Bubble Disease of the Cultivated Button Mushroom, Agaricus bisporus
}

\author{
P. D. Collopy, M. L. Largeteau-Mamoun, C. P. Romaine, and D. J. Royse
}

First, third, and fourth authors: Department of Plant Pathology, The Pennsylvania State University, University Park 16802; and second author: Mushroom Research Station, INRA-Bordeaux, Villenave d'Ornon Cedex, France.

Accepted for publication 28 May 2001.

\begin{abstract}
Collopy, P. D., Largeteau-Mamoun, M. L., Romaine, C. P., and Royse, D. J. 2001. Molecular phylogenetic analyses of Verticillium fungicola and related species causing dry bubble disease of the cultivated button mushroom, Agaricus bisporus. Phytopathology 91:905-912.

Molecular phylogenetic analyses were performed on 40 isolates of Verticillium fungicola collected from various Pennsylvania mushroom farms in 1999 and 28 isolates of Verticillium spp. collected during the last 50 years from various geographic locations. Sequence analysis of internal transcribed spacers 1 and 2 (ITS1 and ITS2) and 5.8S regions of the nuclear ribosomal DNA (rDNA) transcriptional unit and analysis of random amplified polymorphic DNA (RAPD) data were performed for the 68 isolates of Verticillium spp. Identical rDNA sequences were obtained for all 40 Pennsylvania isolates collected during 1999, 13 North American isolates collected during the last 50 years, and the ex-type strain of $V$. fungicola var. aleophilum. Sequence analysis of European isolates revealed a close relationship to the ex-type strain $V$. fungicola var. fungicola. No European-like isolates of V. fungicola var. fungicola
\end{abstract}

ABSTRACT were detected in the collection of North American isolates examined. Results from six decamer RAPD primers strongly indicate the presence of a clonal population of $V$. fungicola among Pennsylvania isolates. In addition, RAPD data delineated a Korean isolate (DC130) and ex-type strain $V$. fungicola var. aleophilum from the North American group. Virulence assays, based on spore inoculation of mushroom pilei, revealed variation corresponding to each neighbor-joining and RAPD grouping. All isolates with rDNA sequence and RAPD grouping similarity to extype strains $V$. fungicola var. aleophilum and $V$. fungicola var. fungicola displayed the highest level of virulence. Based on rDNA sequence and RAPD analyses, isolates displaying reduced or no virulence were distantly related to these two varieties. All results obtained for the analyses of ex-type strain $V$. fungicola var. flavidum suggested that this fungal isolate should not be considered a variety of $V$. fungicola, but rather a distinct species.

Additional keywords: Acremonium strictum, Helicoon sessile, Nectria inventa, Orbilia luteorubella, Tolypocladium parasiticum, V. tenerum.
Verticillium fungicola (Pruess) Hassebrauk is the causal agent of dry bubble disease of the cultivated button mushroom Agaricus bisporus (Lange) Imbach and is worldwide in distribution. Taxonomic revisions have placed $V$. fungicola into section Prostrata and divided it into three different varieties (fungicola, aleophilum, and flavidum) based on morphological taxonomy and pathogenicity studies $(11,24)$. Conidia of $V$. fungicola var. aleophilum are variable in size and shape much like $V$. fungicola var. fungicola. The variety flavidum differs from the other two varieties mainly in its lower optimum temperature, presence of sclerotia, yellowish colonies, pungent odor, and nonpathogenic abilities on Agaricus bisporus. The only consistent difference between $V$. fungicola var. aleophilum and V. fungicola var. fungicola is the temperature maximum for optimal growth $(10,11)$.

Bidochka et al. (4) investigated the production of hydrolytic enzymes and performed pathogenicity assays against a plant and an insect host as a means for gaining insight into the evolution of pathogenicity of Verticillium spp. In addition, the authors performed a sequence analysis of the genus Verticillium with the internal transcribed spacer 1 (ITS1) region and a portion of the relatively more conserved nuclear small subunit of ribosomal RNA (rDNA). These data were used to provide information regarding the genetic variability among 13 different species of

Corresponding authors: D. J. Royse; E-mail address: djr4@psu.edu and C.P. Romaine; E-mail address: cpr2@psu.edu

Publication no. P-2001-0709-01R

(C) 2001 The American Phytopathological Society
Verticillium. Two isolates of $V$. fungicola from two hosts (mushroom and Lepidoptera) were analyzed for their nuclear rDNA phylogeny and extracellular enzyme production. Despite the physiological similarities of these two isolates in their protease, pectinase, and chitinase profiles, rDNA sequence analyses of ITS1 revealed a $49.3 \%$ divergence between isolates. These results did not support monophyly of $V$. fungicola, thus, the possibility of high levels of diversity exist within populations of $V$. fungicola. Therefore, Verticillium may be of polyphyletic origin and, consequently, a form genus.

Genetic variability within isolates of $V$. fungicola was previously investigated by Bonnen and Hopkins (5). The authors used a random amplified polymorphic DNA (RAPD) analysis to examine the within-species variation of this organism. Sixty-six isolates collected over a 45-year period (1950 to 1995) were compared with respect to colony morphology, response to fungicides, virulence, geographic origin, and RAPD grouping. When all 66 isolates were analyzed together, no correlation was found between RAPD grouping, colony morphology, and virulence. However, all recently collected isolates (1993 to 1995) were similar in their fungicide responses, virulence, colony morphologies, geographic origins, and RAPD groupings. This high level of homogeneity within recent isolates of $V$. fungicola contrasts greatly with the results obtained by Bidochka et al. (4) and suggests that a clonal population of $V$. fungicola may be responsible for recent dry bubble outbreaks on commercial mushroom farms.

The objective of this study was to examine the genetic variability within isolates of $V$. fungicola responsible for past and recent dry bubble outbreaks on mushroom farms. Sequence analyses 
of a portion of the nuclear rDNA, specifically the ITS 1 and internal transcribed spacer 2 (ITS2) region and 5.8S rRNA gene, were performed to examine the genetic diversity within this species. Isolates collected from various geographic locations during the past 50 years were included to understand how the genetic diversity of this pathogen has changed over time. A clearer understanding of the genetic structure of temporal $V$. fungicola populations is useful to provide clues on speciation and biogeography.

TABLE 1. List of species/strains, date of collection, isolate code, geographic origin, and source of Verticillium spp. used in this study

\begin{tabular}{|c|c|c|c|c|}
\hline Species/strain & Date & Isolate code & Geographic origin & Source $^{\mathrm{a}}$ \\
\hline$V$. fungicola & 1999 & V01 & Chester County, PA & Claude Fordyce \\
\hline V. fungicola & 1999 & V02 & Chester County, PA & Claude Fordyce \\
\hline V. fungicola & 1999 & V03 & Chester County, PA & Claude Fordyce \\
\hline V. fungicola & 1999 & V04 & Chester County, PA & Claude Fordyce \\
\hline V. fungicola & 1999 & V05 & Chester County, PA & Claude Fordyce \\
\hline V. fungicola & 1999 & V06 & Chester County, PA & Claude Fordyce \\
\hline V. fungicola & 1999 & V07 & Chester County, PA & Claude Fordyce \\
\hline V. fungicola & 1999 & V08 & Chester County, PA & Claude Fordyce \\
\hline V. fungicola & 1999 & V09 & Chester County, PA & Claude Fordyce \\
\hline V. fungicola & 1999 & V10 & Chester County, PA & Claude Fordyce \\
\hline V. fungicola & 1999 & V11 & Chester County, PA & Claude Fordyce \\
\hline V. fungicola & 1999 & V12 & Chester County, PA & Claude Fordyce \\
\hline V. fungicola & 1999 & V13 & Chester County, PA & Claude Fordyce \\
\hline V. fungicola & 1999 & V14 & Chester County, PA & Claude Fordyce \\
\hline V. fungicola & 1999 & V15 & Chester County, PA & Claude Fordyce \\
\hline V. fungicola & 1999 & V16 & Chester County, PA & Claude Fordyce \\
\hline V. fungicola & 1999 & V17 & Chester County, PA & Claude Fordyce \\
\hline V. fungicola & 1999 & V18 & Chester County, PA & Claude Fordyce \\
\hline V. fungicola & 1999 & V19 & Chester County, PA & Claude Fordyce \\
\hline V. fungicola & 1999 & V20 & Delaware & Claude Fordyce \\
\hline V. fungicola & 1999 & V21 & Berks County, PA & Claude Fordyce \\
\hline V. fungicola & 1999 & V22 & Berks County, PA & Claude Fordyce \\
\hline V. fungicola & 1999 & V23 & Berks County, PA & Claude Fordyce \\
\hline V. fungicola & 1999 & V24 & Berks County, PA & Claude Fordyce \\
\hline V. fungicola & 1999 & V25 & Berks County, PA & Claude Fordyce \\
\hline V. fungicola & 1999 & V26 & Berks County, PA & Claude Fordyce \\
\hline V. fungicola & 1999 & V27 & Chester County, PA & Claude Fordyce \\
\hline V. fungicola & 1999 & V28 & Chester County, PA & Claude Fordyce \\
\hline V. fungicola & 1999 & V29 & Chester County, PA & Claude Fordyce \\
\hline V. fungicola & 1999 & V30 & Chester County, PA & Claude Fordyce \\
\hline V. fungicola & 1999 & V31 & Chester County, PA & Claude Fordyce \\
\hline V. fungicola & 1999 & V32 & Chester County, PA & Claude Fordyce \\
\hline V. fungicola & 1999 & V33 & Chester County, PA & Claude Fordyce \\
\hline V. fungicola & 1999 & V34 & Chester County, PA & Claude Fordyce \\
\hline V. fungicola & 1999 & V35 & Chester County, PA & Claude Fordyce \\
\hline V. fungicola & 1999 & V36 & Chester County, PA & Claude Fordyce \\
\hline V. fungicola & 1999 & V37 & Chester County, PA & Claude Fordyce \\
\hline V. fungicola & 1999 & V38 & Chester County, PA & Claude Fordyce \\
\hline V. fungicola & 1999 & V39 & Chester County, PA & Claude Fordyce \\
\hline V. fungicola & 1999 & V40 & Chester County, PA & Claude Fordyce \\
\hline V. fungicola & 1951 & DC114 & Chester County, PA & PSUCC \\
\hline V. fungicola & 1969 & DC116 & Chester County, PA & PSUCC \\
\hline V. fungicola & 1958 & DC120 & Pennsylvania & PSUCC \\
\hline V. fungicola & Early 1950 s & DC121 & Unknown & PSUCC \\
\hline V. fungicola & 1950 & DC123 & Michigan & PSUCC \\
\hline V. fungicola & Early 1950s & DC124 & Unknown & PSUCC \\
\hline V. fungicola & 1971 & DC130 & Korea & PSUCC \\
\hline V. fungicola & Early 1970s & DC131 & Switzerland & PSUCC \\
\hline V. fungicola & 1971 & DC134 & Chester County, PA & PSUCC \\
\hline V. fungicola & 1978 & DC138 & Berks County, PA & PSUCC \\
\hline V. fungicola & 1979 & DC142 & Quebec, Canada & PSUCC \\
\hline V. fungicola & 1979 & DC145 & California & PSUCC \\
\hline V. fungicola & 1981 & DC150 & Ocean View, CA & PSUCC \\
\hline V. fungicola & 1982 & DC165 & Lawrence County & PSUCC \\
\hline V. fungicola & 1986 & DC185 & Chester County, PA & PSUCC \\
\hline V. fungicola & 1990 & DC226 & Unknown & PSUCC \\
\hline V. fungicola & 1993 & DC253 & University Park, PA & PSUCC \\
\hline V. fungicola & 1985 & DC259 & Canada & PSUCC \\
\hline V. fungicola & 1988 & DC262 & Canada & PSUCC \\
\hline V. fungicola & 1997 & VCTC & Indre et Loire, France & INRA-Bx \\
\hline V. fungicola & 1994 & VK & Meurthe et Moselle, France & INRA-Bx \\
\hline V. fungicola & 1987 & VF & Indre et Loire, France & INRA-Bx \\
\hline V. fungicola & 1993 & VV1 & Gironde, France & INRA-Bx \\
\hline V. fungicola & 1961 & 895 & Canada & UAMH \\
\hline V. fungicola var. aleophilum & 1980 & $\mathrm{AL}$ & Netherlands & CBS 357.80 \\
\hline V. fungicola var. flavidum & 1980 & $\mathrm{FL}$ & Villeurbanne, France & CBS 342.80 \\
\hline V. fungicola var. fungicola & 1934 & Vfvf & United Kingdom & CBS 440.34 \\
\hline V. tenerum (Nectria inventa) & 1916 & $\mathrm{Ni}$ & United Kingdom & CBS 112.16 \\
\hline
\end{tabular}

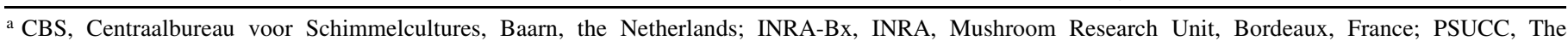

Pennsylvania State University culture collection; UAMH, University of Alberta Microfungus Collection and Herbarium, Edmonton, Alberta, Canada. 
In addition to comparing rDNA sequences of various isolates collected over the past 50 years, a RAPD analysis was performed. This allowed for the genetic assessment of isolates collected during 1999 from 27 southeastern Pennsylvania mushroom farms.

\section{MATERIALS AND METHODS}

Cultures. Forty isolates of $V$. fungicola were isolated from Agaricus bisporus basidiomes collected at 27 mushroom farms in southeastern Pennsylvania in 1999. Single spore cultures were generated from each isolate to ensure genetic uniformity before molecular analysis. Ex-type strains for all three varieties of $V$. fungicola were obtained from Centraalbureau voor Schimmelcultures (Baarn, the Netherlands). Sources and origins of all other isolates used in this study are listed in Table 1.

DNA extraction. Single spore isolates were grown for 5 days at room temperature in $50 \mathrm{ml}$ of $2 \%$ malt extract broth contained in 250-ml Erlenmeyer flasks. Mycelial mats were collected by vacuum filtration, washed with sterile double-distilled $\mathrm{H}_{2} \mathrm{O}$, and allowed to air dry. Genomic DNA was extracted with a DNA isolation kit (Puregene; Gentra Systems Inc., Minneapolis, MN) according to the manufacturer's protocols for DNA isolation from 10 to $20 \mathrm{mg}$ of fungal tissue with modifications as follows: harvested mycelium (12 to $15 \mathrm{mg}$ ) was placed into sterile microfuge tubes and suspended in $300 \mu \mathrm{l}$ of cell lysis solution with $1.5 \mu \mathrm{l}$ of proteinase $\mathrm{K}$ solution $(20 \mathrm{mg} / \mathrm{ml})$. Samples were finely ground with a micropestle, vortexed, and incubated at $55^{\circ} \mathrm{C}$ for $2 \mathrm{~h}$. The manufacturer's protocol was followed beginning with RNase treatment of cell lysates.

Polymerase chain reaction amplification of ITS1 and ITS2 regions and 5.8S rDNA. DNA (10 ng) was amplified in reaction mixtures $(23.5 \mu \mathrm{l})$ containing $50 \mathrm{mM}$ Tris $(\mathrm{pH} 8.3), 0.25 \mathrm{mg} / \mathrm{ml}$ of bovine serum albumin (BSA), $2 \%$ sucrose, $0.1 \mathrm{mM}$ Cresol Red, $0.2 \mathrm{mM}$ dNTPs, $2 \mathrm{mM} \mathrm{MgCl}, 0.1 \%$ Triton, 1.0 units of Taq DNA polymerase (Promega, Madison, WI), and $0.5 \mu \mathrm{M}$ each of primer ITS1 (5'-TCCGTAGGTGAACCTGCGG-3') (26) and ALR0 (5'CATATGCTTAAGTTCAGCGGG-3'). Reactions were performed in $0.2-\mathrm{ml}$ thinwall polymerase chain reaction (PCR) tubes with a thermocycler (PTC-100TM; MJ Research Inc., Watertown, MA) with the following program: 1 cycle at $94^{\circ} \mathrm{C}$ for $2 \mathrm{~min} ; 35$ cycles at $94^{\circ} \mathrm{C}$ for $15 \mathrm{~s}, 57^{\circ} \mathrm{C}$ for $30 \mathrm{~s}$, and $72^{\circ} \mathrm{C}$ for $45 \mathrm{~s}$; and 1 cycle at $72^{\circ} \mathrm{C}$ for $4 \mathrm{~min}$.

Sequencing of PCR products. Amplified PCR products were purified directly by a PCR prep system (Wizard; Promega) according to the manufacturer's protocol. Purified amplification products $(10 \mathrm{ng})$ were sequenced in $5-\mu \mathrm{l}$ reactions containing $1-\mu \mathrm{l}$ terminator (BigDye; Perkin-Elmer Applied Biosystems, Foster City, CA), $1 \mu$ halfBD (HBD100; Genpak Inc., Stony Brook, $\mathrm{NY}$ ), and $0.5 \mathrm{mM}$ of each PCR primer. Sequencing reactions were performed in 0.2-ml thinwall PCR tubes with a thermocycler (MJ Research) with the following program: 1 cycle at $92^{\circ} \mathrm{C}$ for $90 \mathrm{~s}, 50^{\circ} \mathrm{C}$ for $15 \mathrm{~s}$, and $60^{\circ} \mathrm{C}$ for $4 \mathrm{~min}$; and 25 cycles at $92^{\circ} \mathrm{C}$ for $30 \mathrm{~s}, 50^{\circ} \mathrm{C}$ for $15 \mathrm{~s}, 60^{\circ} \mathrm{C}$ for $4 \mathrm{~min}$. Sequence data from isolates

TABLE 2. Nucleotide variation of the internal transcribed spacer 1 (ITS1), $5.8 \mathrm{~S}$, and ITS2 of ex-type strains of Verticillium fungicola and V. tenerum

\begin{tabular}{lccc}
\hline $\begin{array}{l}\text { Isolates compared } \\
\text { a }\end{array}$ & $\begin{array}{c}\text { No. of } \\
\text { variable sites }\end{array}$ & $\begin{array}{c}\text { Total sites } \\
\text { compared }\end{array}$ & $\begin{array}{c}\text { Percent } \\
\text { variation }\end{array}$ \\
\hline Vfvf-AL-FL-Ni & 171 & 490 & 34.9 \\
Vfvf-AL-Ni & 134 & 478 & 28.0 \\
Vfvf-AL-FL & 80 & 485 & 16.5 \\
Vfvf vs. FL & 79 & 483 & 16.4 \\
AL vs. FL & 75 & 485 & 15.5 \\
Vfvf vs. AL & 7 & 466 & 1.5 \\
\hline
\end{tabular}

a $\mathrm{Vfvf}=V$. fungicola var. fungicola $; \mathrm{AL}=V$. fungicola var. aleophilum $; \mathrm{FL}=$

V. fungicola var. flavidum; and $\mathrm{Ni}=V$. tenerum.
Vfvf, V17, AL, FL, Ni, VV1, DC130, DC116, and DC114 were deposited in GenBank as representatives of all samples in this study under Accession Nos. AF324874 to AF324882, respectively.

DNA sequence analysis. Sequence data was analyzed with the Wisconsin Package (Genetics Computer Group, Madison, WI). DNA sequences of the ITS1, ITS2, and 5.8S rDNA were aligned and compared independently for the entire set of $V$. fungicola isolates using Clustal W software for multiple sequence alignment $(12,23)$. Sequence analyses were performed using phylogenetic analysis using parsimony (PAUP; version 4.0, Sinauer Associates, Sunderland, MA). Nucleotide distances were calculated by the Jukes-Cantor (13) and Kimura two-parameter models (14) with gaps treated as missing data, and phylogenetic inferences were performed by the neighbor-joining (NJ) method (21).

Representative sequence contigs from each group resulting from the $\mathrm{NJ}$ analysis of isolates in Table 1 were used for comparison to the nucleotide database at the National Center for Biotechnology Information (NCBI, Bethesda, MD). Basic local alignment search tool for nucleotides (BLASTnr) was used to query all nucleotide databases at the NCBI (1). Organisms with sequence matches for ITS1, 5.8S, and ITS2 rRNA gene sequences were used in an NJ analysis using the Jukes-Cantor (13) and Kimura two-parameter models (14) with gaps treated as missing data, and a maximum parsimony (MP) analysis using the heuristic search option with gaps treated as missing data and starting trees obtained through stepwise addition. Duplicate matches for searches were not included in the analysis. Bootstrap tests with 1,000 replications (8) were conducted for sequence analyses to examine reliability of interior branches. V. tenerum (Ni) was designated as the outgroup for all sequence analyses.

RAPD analysis. DNAs (10 ng) were amplified in reaction mixtures $(15 \mu \mathrm{l})$ containing $50 \mathrm{mM}$ Tris $(\mathrm{pH} 8.3), 0.25 \mathrm{mg} / \mathrm{ml}$ of BSA,

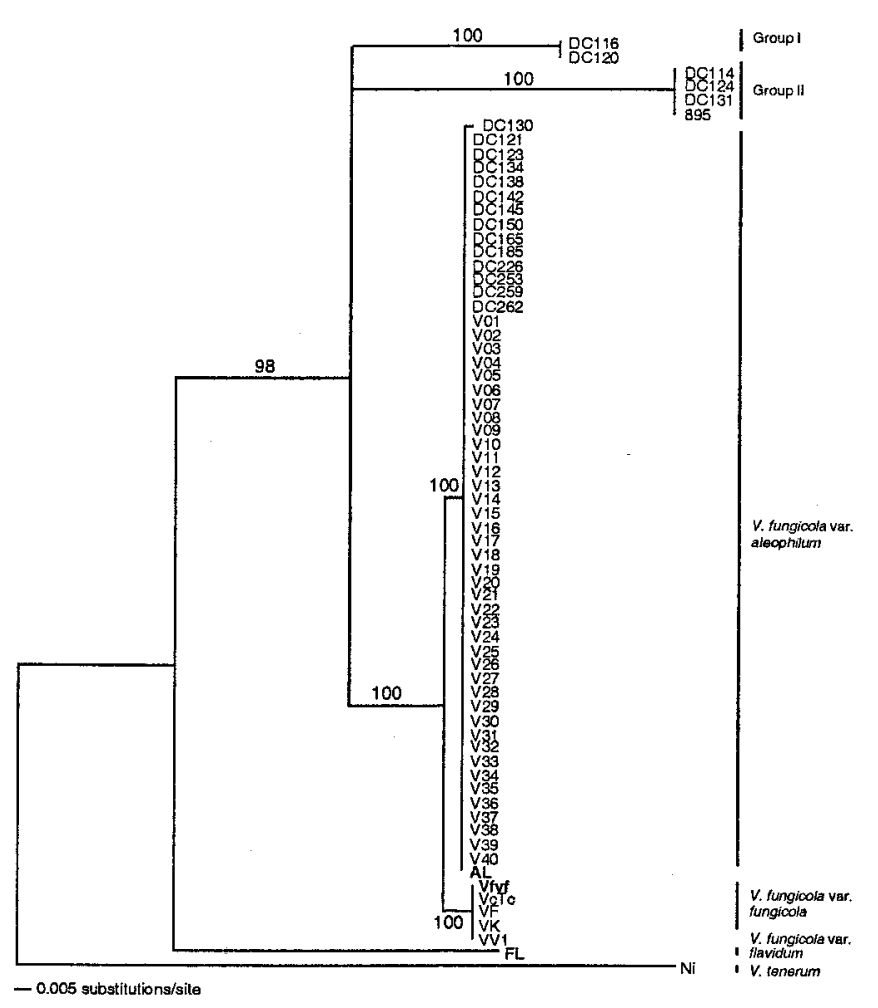

Fig. 1. Phylogenetic relationships based on rDNA sequence analysis of Verticillium fungicola isolates and related taxa. Inferences were constructed using the neighbor-joining method with distance analysis calculated with the Kimura two-parameter model. Bootstrap values shown at branches were obtained from 1,000 replications. Vertical bars represent groups inferred from this analysis. Ex-type strains for varieties of $V$. fungicola are designated in bold font. 
$2 \%$ sucrose, $0.1 \mathrm{mM}$ Cresol Red, $0.2 \mathrm{mM}$ dNTPs, $2 \mathrm{mM} \mathrm{MgCl}$, 1.0 units of Taq DNA polymerase (Promega), and $0.5 \mu \mathrm{M}$ decamer primer. Reactions were performed in 0.2-ml thinwall PCR tubes with a thermocycler (PTC-100TM; MJ Research) with the program as follows: 1 cycle at $94^{\circ} \mathrm{C}$ for 2 min and 35 cycles at $94^{\circ} \mathrm{C}$ for $1 \mathrm{~min}, 37^{\circ} \mathrm{C}$ for $2 \mathrm{~min}$, and $72^{\circ} \mathrm{C}$ for $2 \mathrm{~min}$. Products were visualized on 1.5\% NuSieve 3:1 agarose gels (BioWhittaker Molecular Applications, Rockland, ME) containing $0.05 \mu \mathrm{g}$ of ethidium bromide per milliliter. Primers that produced polymorphisms were chosen based on previous work by Bonnen and Hopkins (5). Primers 1 (5'-CCTGGGCTTC-3'), 17 (5'-CCTGGGCCTC-3'), 32 (5'-GGGGCCTTAA-3'), 77 (5'-GAGCACCAGG$\left.3^{\prime}\right), 370$ (5'-TCAGCCAGCG-3'), and 489 (5'-CGCACGCACA-3') were obtained from the Nucleic Acid Protein Service Unit of the Biotechnology Laboratory of the University of British Columbia in Vancouver.

Pathogenicity assay. Basidiomes of Agaricus bisporus were harvested with the partial veil still intact from The Pennsylvania State University Mushroom Test Demonstration Facility and inoculated the same day with a $V$. fungicola spore suspension. Eighteen representative isolates of seven different RAPD groupings were used for this assay. Virulence tests were performed and rated for each isolate as previously described by Bonnen and Hopkins (5). Stipes were removed from all basidiomes prior to inoculation to retard pileus opening and basidiospore release. Pilei were inoculated with a spore suspension containing $1 \times 10^{6}$ conidia per $\mathrm{ml}$ and rated as follows: $0=$ no symptoms; $1=$ faint rings around inoculation site; 2 = light brown rings around inoculation site; $3=$ dark brown rings at inoculation site; $4=$ dark brown rings, some sporulation, and some pitting of the pileus tissue at inoculation site; and $5=$ symptoms extend beyond the inoculation site, severe pitting of the tissue, and profuse sporulation.

\section{RESULTS}

Amplified PCR products obtained from the ITS1 and ITS2 gene regions and 5.8S rDNA yielded fragments approximately $500 \mathrm{bp}$ in length. Purification and sequencing of amplicons produced 456 to $476 \mathrm{bp}$ of readable sequence for 68 samples after sequences were assembled and manually trimmed. An alignment of DNA sequences listed in Table 1 generated a total of 503 sites, including gaps, for sequence analyses. Variation within the entire alignment was $40.0 \%$, with internal variation of the ITS1, 5.8S, and ITS2 gene regions of $66.1,11.0$, and $44.2 \%$, respectively. Most variation observed within these regions was attributable to sequences obtained from $V$. fungicola var. flavidum and $V$. tenerum. When these samples were removed from the alignment, variation within a total number of 494 sites dropped to $18.2 \%$ and variation within the ITS1, 5.8S, and ITS2 gene regions dropped to $35.8,0.0$, and $19.9 \%$, respectively, for sequences of 456 to $476 \mathrm{bp}$. Transitions accounted for most of the observed substitutions with transition/transversion ratios of $1.1,5.8$, and 1.4 for the ITS1, $5.8 \mathrm{~S}$, and ITS2 gene regions when all sequence contigs were compared.

Independent nucleotide sequence alignments between ex-type strain varieties of $V$. fungicola showed variation of $16.5 \%$. Most of the variation was due to nucleotide differences between sequences of $V$. fungicola var. fungicola and $V$. fungicola var. flavidum $(16.4 \%)$, followed by differences between sequences of $V$. fungicola var. aleophilum and V. fungicola var. flavidum (15.5\%). Very low nucleotide sequence divergence $(1.5 \%)$ was observed between ex-type strains $V$. fungicola var. fungicola and $V$. fungicola var. aleophilum. Sequence divergences within alignments of $V$. fungicola ex-type strains and the ex-type strain of V. tenerum were very high (Table 2 ).

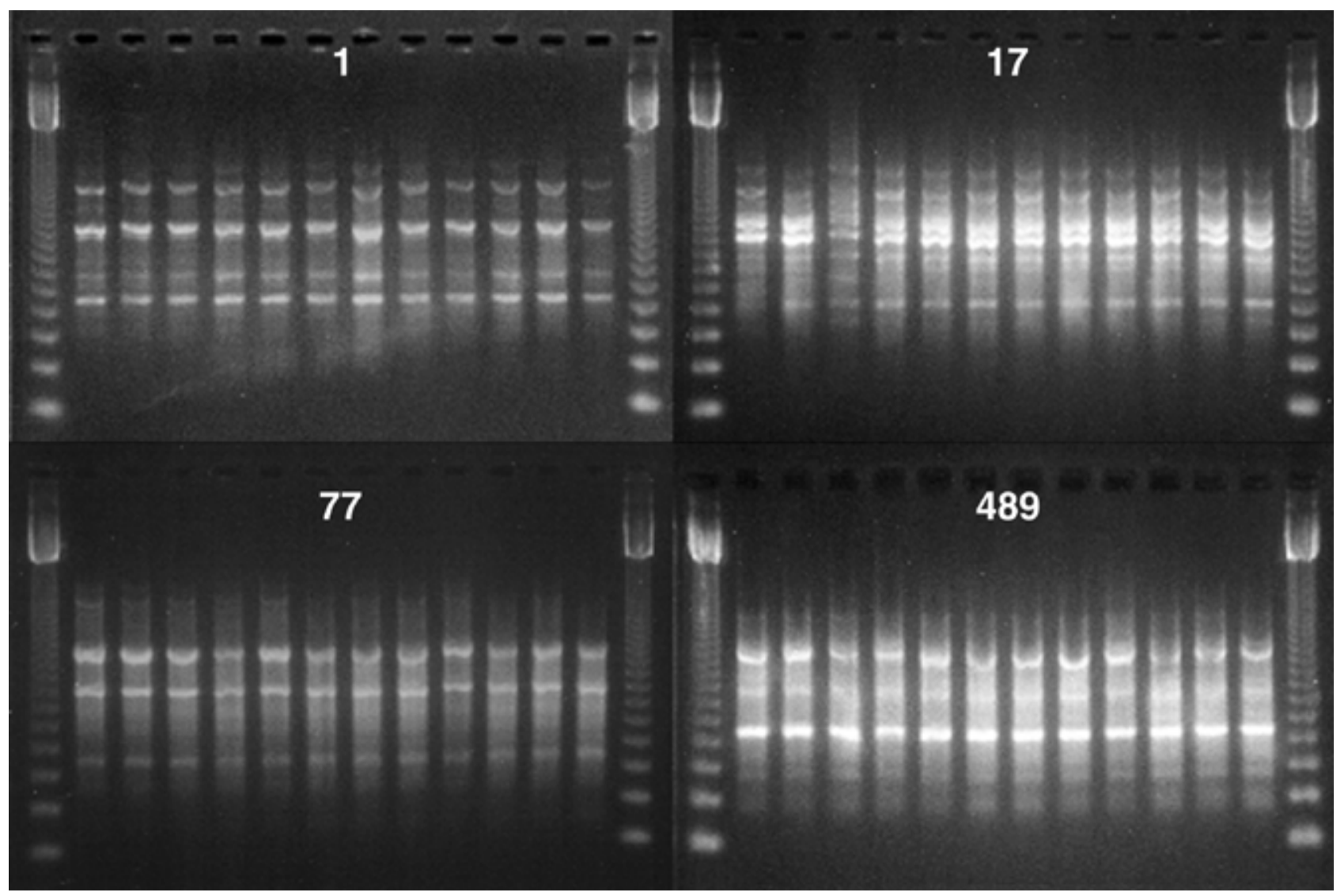

Fig. 2. Random amplified polymorphic DNA analyses of 12 selected isolates of Verticillium fungicola collected from Pennsylvania mushroom farms in 1999. Isolates V7, V9, V11, V13, V15, V17, V19, V25, V27, V32, V34, and V37 are shown left to right for each primer. Numbers listed above each gel refer to UBC primers (Vancouver, BC). Each group of amplification products are flanked by a 123-bp DNA ladder. 
An NJ distance analysis for the entire set of sequence contigs (rDNA) placed isolates into four different groups. All isolates collected from Pennsylvania mushroom farms in 1999 were placed in group $V$. fungicola var. aleophilum with 14 isolates from The Pennsylvania State University culture collection (PSUCC). No sequence variation existed within $V$. fungicola var. aleophilum, with the exception of a single transition substitution within the ITS2 gene region of isolate DC130 from Korea. Similarly, no sequence variation was observed within groups I and II derived from this analysis (Fig. 1). V. tenerum (Ni) was defined as the outgroup for rooting the $\mathrm{NJ}$ tree in order to display the relatedness of $V$. fungicola to its respective genus.

Results obtained from sequence analyses were further supported by RAPD analysis. All isolates collected from Pennsylvania mushroom farms during 1999 provided identical RAPD patterns for all primers screened. Figure 2 shows RAPD data of four different primers screened on 12 recent isolates of $V$. fungicola. RAPD analysis of isolates from all groups produced from $\mathrm{NJ}$ analysis revealed distinct banding patterns for each $\mathrm{NJ}$ grouping and further delineated isolates DC130 and the ex-type strain of $V$. fungicola var. aleophilum from all other isolates of the $V$. fungicola var. aleophilum group (Fig. 3, lanes 6 and 7). A total of seven different RAPD groupings were observed from all isolates identified as $V$. fungicola. Samples that produced unique RAPD patterns were consistent with those samples that yielded unique sequences of the ITS1, 5.8S, and ITS2 rDNA (Fig. 3, lanes 18 and 19). The unique RAPD pattern observed from $V$. tenerum was not counted as an RAPD grouping and was only included as a positive control for amplification success. Similarly, negative control reactions with water rather than template DNA did not produce DNA bands (data not shown).

Each of the 18 isolates shown in Figure 3 was assessed for virulence level on Agaricus bisporus. All isolates of groups $V$. fungicola var. aleophilum and V. fungicola var. fungicola induced the most severe disease symptoms on Agaricus bisporus pilei. Neither sterile $\mathrm{H}_{2} \mathrm{O}$ used as a negative control produced symptoms nor did some isolates of the PSUCC (DC124 and DC131), V. tenerum, and $V$. fungicola var. flavidum.

Results of queried sequences in the nucleotide databases at the NCBI yielded sequence matches exclusively for ITS1, 5.8S, and ITS2 nuclear rDNA. The top three matches for each queried sequence were downloaded and used for sequence analysis. A total of 12 sequences representing eight different fungal genera produced sequence matches with $\mathrm{E}$ values ranging from 0 to 1.0E - 124 (Table 3). Isolates V17 and Vfvf both produced matches for Cordyceps nutans and Paecilomyces sp. KACC40219. Isolate DC120 matched two identical rDNA sequences of Beauveria parasitica (only one included for sequence analysis).

Alignment of sequences listed in Table 3 produced 494 sites with $47.2 \%$ variability within the entire alignment. An MP analysis produced a single most parsimonious tree with a length of 471 steps, and consistency and retention indices of 0.73 and 0.88 , respectively (data not shown). V. tenerum was chosen as the outgroup for this and all subsequent sequence analyses. A phylogenetic tree generated from an NJ analysis using the Kimura twoparameter model with 1,000 bootstrap replicates was identical in tree topology to the MP tree (Fig. 4).

\section{DISCUSSION}

A total of four groups were inferred from an $\mathrm{NJ}$ analysis of the ITS1, 5.8S, and ITS2 sequences. Two of these groups, $V$. fungicola var. aleophilum and $V$. fungicola var. fungicola, were comprised of isolates responsible for recent dry bubble outbreaks in Europe and North America, with the exception of one Korean isolate (DC130). Observed levels of divergence between European and North American isolates were consistent with the geographic location of origin. European isolates had identical rDNA sequences to
V. fungicola var. fungicola. Currently, no isolates of the European group have been detected on North American mushroom farms. Isolates causing dry bubble disease in North America have identical ITS1, 5.8S, and ITS2 rDNA sequence to V. fungicola var. aleophilum. Although $V$. fungicola var. aleophilum has been collected in Europe (24), $V$. fungicola var. fungicola is the predominant causal agent of dry bubble on Agaricus bisporus in that continent. Sequence analyses of the green mold mushroom pathogen, Trichoderma harzianum, have revealed a similar phenomenon of geographic isolation. Two biotypes (Th2 and Th4) of Trichoderma harzianum were responsible for recent green mold epidemics in Europe and North America, respectively (6,7,18-20).

Previous morphological and pathogenicity analyses have described three varieties in the $V$. fungicola species complex $(11,24)$. Molecular sequence analyses performed in this study support only two varieties in this species complex. Sequence data indicated that $V$. fungicola var. flavidum and V. tenerum were distantly related to other strains examined and were not considered part of any group. Sequence divergence among all ex-type strain varieties of $V$. fungicola was at $16.5 \%$, with $V$. fungicola var. flavidum (FL) responsible for most of the observed variation. These results indicate that $V$. fungicola var. flavidum should not be part of the $V$. fungicola species complex. Based on sequence analyses and the inability of $V$. fungicola var. flavidum to cause disease on Agaricus

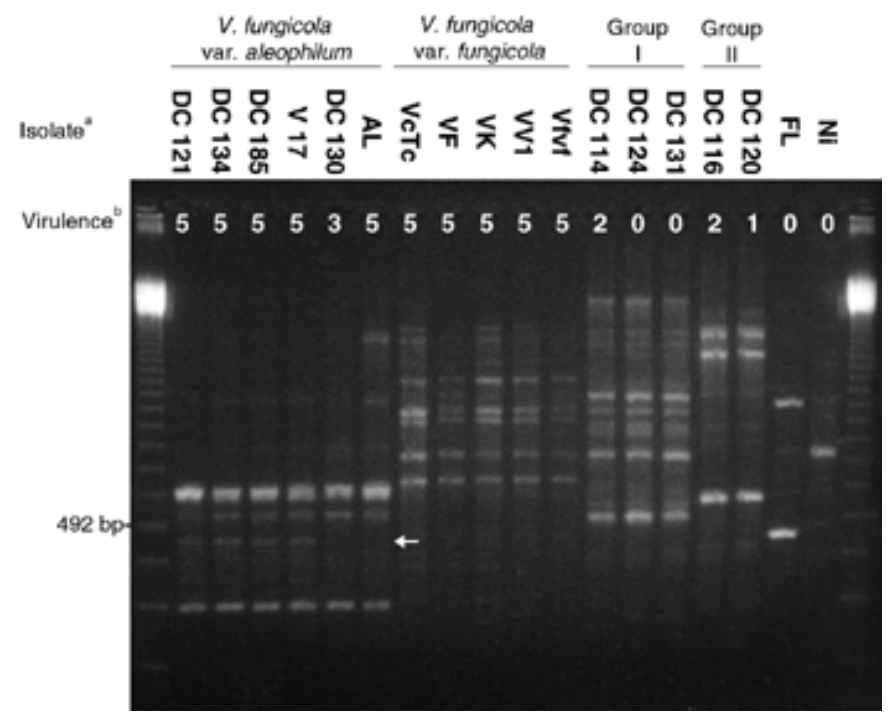

Fig. 3. Random amplified polymorphic DNA (RAPD) analysis showing profiles generated with UBC primer 370 for each group obtained from neighbor-joining (NJ) sequence analysis. Horizontal lines above gel designate groups derived from $\mathrm{NJ}$ analysis of rDNA sequences. Ex-type strains of Verticillium fungicola var. flavidum (FL, lane 18) and V. tenerum (Ni, lane 19) produced unique RAPD patterns not found with any other isolates. Arrow indicates differences in RAPD patterns from Korean isolate DC130 (lane 6) and the ex-type strain of V. fungicola var. aleophilum (AL, lane 7) compared with other isolates in group I. Isolates are flanked with a 123-bp DNA ladder. Results of pathogenicity assay for each isolate are shown below each sample well. Virulence of Verticillium spp. on Agaricus bisporus pilei was assessed 5 days after inoculation at room temperature. Superscript a, V17 = Pennsylvania strain of $V$. fungicola collected in 1999; DC114, DC116, DC120, DC121, DC124, DC130, DC131, DC134, and DC134 = isolates obtained from The Pennsylvania State University disease culture collection; VcTc, VF, VK, and VV1 = European strains of $V$. fungicola; $\mathrm{AL}=$ ex-type strain of $V$. fungicola var. aleophilum; FL = ex-type strain of $V$. fungicola var. flavidum; Vfvf = ex-type strain of $V$. fungicola var. fungicola; and $\mathrm{Ni}=$ ex-type strain of $V$. tenerum. Superscript $\mathrm{b}$, virulence expression was based on a scale of 0 to 5 as follows: $0=$ no symptoms; $1=$ faint rings around inoculation site; $2=$ light brown rings around inoculation site; $3=$ dark brown rings at inoculation site; $4=$ dark brown rings, some sporulation, and some pitting of the cap tissue at inoculation site; and $5=$ symptoms extend beyond the inoculation site, severe pitting of the tissue and profuse sporulation (5). 
bisporus, we suggest further investigations and possibly the removal of this variety from the $V$. fungicola species complex in order to result in monophyly for the two remaining varieties, $V$. fungicola var. aleophilum and $V$. fungicola var. fungicola.

Verticillium as a morphologically described genus is thought to be polyphyletic. In this study, sequence divergence among Verticillium ex-type strains was $34.9 \%$, and sequence divergence among ex-type strains $V$. fungicola var. aleophilum and $V$. fungicola var. fungicola with $V$. tenerum was $28.0 \%$. The high level of sequence divergence between these two varieties of $V$. fungicola and $V$. tenerum suggest that $V$. fungicola var. aleophilum and $V$. fungicola var. fungicola may not be species of Verticillium, in the strictest sense, based on sequence comparisons with the ex-type strain of the genus, $V$. tenerum.

All members of the $\mathrm{NJ}$ grouping corresponding to $V$. fungicola var. aleophilum produced identical RAPD patterns, with the exception of the ex-type strain of $V$. fungicola var. aleophilum and strain DC130 from Korea (Fig. 2). These isolates produced RAPD profiles similar to, but not identical to all other isolates of the $V$. fungicola var. aleophilum group. RAPD analysis revealed at least seven different categories of isolates identified and misidentified as V. fungicola. Previous work by Bonnen and Hopkins (5) identified only four RAPD groupings. The additions of European isolates and the ex-type strains of $V$. fungicola to these analyses were responsible for the observed increase in the number of RAPD groupings.

The higher growth rate of the ex-type strain $V$. fungicola var. aleophilum at $30^{\circ} \mathrm{C}$ compared with 20 to $24^{\circ} \mathrm{C}$ for ex-type strain V. fungicola var. fungicola initially was used to distinguish these two varieties (11). Previous analyses performed by Lambert (15) indicated growth rate discrepancies between Korean and North American isolates identified as $V$. fungicola. Lambert (15) observed a higher growth rate at $30^{\circ} \mathrm{C}$ for Korean isolates compared with the higher growth rate of North American isolates at $21^{\circ} \mathrm{C}$. Two of these isolates, DC130 and DC123, were included in our study. Based on Lambert's (15) observations, it appears that isolate DC123 is more closely related to V. fungicola var. fungicola; however, based on our results obtained from sequence and RAPD analyses, isolate DC123 is more closely related to $V$. fungicola var. aleophilum. The lower optimal temperature for growth of isolate DC123, and the similarity to all isolates of $V$. fungicola collected in 1999, may explain why this biotype is the predominant cause of dry bubble on North America farms.

Isolates misidentified as $V$. fungicola from PSUCC that were placed into groups I and II were not as virulent as isolates from groups $V$. fungicola var. aleophilum and V. fungicola var. fungicola. Isolates from groups I and II have not been recently detected on mushroom farms and should not be considered strains of $V$. fungicola based on rDNA sequence analysis and virulence assays. The lack of diversity in fungi isolated from mushroom farms observed from our data may be due to a change in the practices regarding the casing of mushroom crops. Because of the movement toward the use of pasteurized peat moss as a casing layer in the 1970s, the use of soil as a casing material became less common (22). The adoption of peat moss as primary casing substrate increased the uniformity of casing material from mushroom farm to mushroom farm. Although early studies indicated the usefulness of pasteurizing soil with aerated-steam to reduce the occurrence of mushroom pathogens in casing material $(16,17)$, the primary use of pasteurized peat moss today may explain why a more genetically uniform group of fungi are responsible for dry bubble outbreaks.

Previous phylogenetic analyses on the genus Verticillium have not supported the monophyly of $V$. fungicola based on sequences of ITS1 and a portion of the $18 \mathrm{~S}$ rRNA gene (4). Our sequence analyses of $V$. fungicola using rDNA sequences from PCR amplification products and NCBI nucleotide databases revealed four major groups containing strains identified as $V$. fungicola. Only strains with similar rDNA sequences to two ex-type strains, $V$. fungicola var. aleophilum and V. fungicola var. fungicola, grouped together in the sister groups.

The ex-type strain of $V$. fungicola var. flavidum grouped with Acremonium strictum Gams, Helicoon sessile Morgan, and Orbilia luteorubella Webster and Descal. These observations suggest that $V$. fungicola var. flavidum should not be considered a variety of $V$. fungicola because of its high sequence divergence of the ITS1, 5.8S, and ITS2 rRNA gene region from the other two varieties of this species. The current taxonomic status of this species is ambiguous and should be examined further to determine its relationship to species of Acremonium, Helicoon, and Orbilia.

Three isolates from the PSUCC (DC114, DC124, and DC131) and one isolate from the University of Alberta Microfungus Collection and Herbarium (895) grouped closely to two sequences of V. lamellicola (UAMH 2055 and 4785) and a sequence submitted to the NCBI nucleotide databases as Gaemannomyces sp. 159 (CBS 387.81). Lambert (15) previously suggested that isolate DC124 was a species other than $V$. fungicola, presumably $V$. lamellicola, based on morphology, pathogenicity, and growth characteristics. Strain DC114 exhibited lower pathogenicity than members of groups $V$. fungicola var. aleophilum and $V$. fungicola var. fungicola in our virulence assay, whereas DC124 and DC131 were not pathogenic (895 was not tested). Previous phylogenetic sequence analysis of Gaemannomyces sp. 159 (CBS 387.81) produced ambiguous results within sequence data from the Gaemannomyces-Phialophora complex (25), indicating that this

TABLE 3. Basic local alignment search tool for nucleotides (BLASTnr) results of internal transcribed spacer 1 (ITS1), 5.8S, and ITS2 rDNA sequence data ${ }^{\text {a }}$

\begin{tabular}{|c|c|c|c|c|}
\hline Isolate match & Organism & GenBank Accession No. & E values & $\%$ Identity (bp) \\
\hline DC120 & Beauveria parasitica 38002 & BPU35305, BPU19039 & $1.0 \mathrm{E}-135$ & 94.5 \\
\hline DC120 & Tolypocladium parasiticum (B. parasitica) ATCC52203 & TP58SRR & $1.0 \mathrm{E}-135$ & 94.5 \\
\hline DC114 & Gaeumannomyces sp. 159 & GSP10040 & $1.0 \mathrm{E}-128$ & 98.4 \\
\hline DC114 & Verticillium lamellicola UAMH 2055 & AF108471 & $1.0 \mathrm{E}-128$ & 98.4 \\
\hline DC114 & Verticillium lamellicola UAMH 4785 & AF108480 & $1.0 \mathrm{E}-132$ & 98.8 \\
\hline V17 & Cordyceps sp. 97009 & AB027378 & $0.0 \mathrm{E}+00$ & 91.5 \\
\hline V17, Vfvf & Cordyceps nutans KACC500169 & AF224274 & $0.0 \mathrm{E}+00,1.0 \mathrm{E}-164$ & $91.4,92.9$ \\
\hline V17, Vfvf & Paecilomyces sp. KACC40219 & AF224690 & $1.0 \mathrm{E}-168,0.0 \mathrm{E}+00$ & $92.2,92.1$ \\
\hline Vfvf & Paecilomyces sp. KACC40221 & AF208525 & $0.0 \mathrm{E}+00$ & 91.7 \\
\hline $\mathrm{FL}$ & Acremonium strictum ATCC $34717^{\mathrm{b}}$ & ASU57671 & $1.0 \mathrm{E}-157$ & 89.8 \\
\hline FL & Helicoon sessile 129 & HSU72605 & $1.0 \mathrm{E}-124$ & 93.0 \\
\hline FL & Orbilia luteorubella 125 & OLU72604 & $1.0 \mathrm{E}-124$ & 93.0 \\
\hline
\end{tabular}

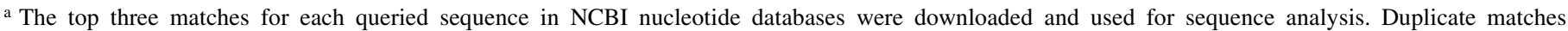
for searches were not included in analyses Vfvf $=V$. fungicola var. fungicola; $\mathrm{AL}=$ V. fungicola var. aleophilum; FL = V. fungicola var. flavidum; and $\mathrm{Ni}=$ V. tenerum.

${ }^{\mathrm{b}}$ Ex-type strain of Acremonium strictum. 
strain has most likely been misidentified as a species of Gaemannomyces. Based on sequence data from this analysis, strains DC114, DC124, DC131, and 895 are more closely related to $V$. lamellicola and should not be considered strains of $V$. fungicola. Likewise, Gaemannomyces sp. 159 is more closely related to $V$. lamellicola than to the Gaemannomyces-Phialophora complex.

Isolates DC116 and DC120 from the PSUCC were grouped with close similarity to sequences obtained from Tolypocladium parasiticum (Beauveria parasitica), a fungal parasite of rotifers (3). The genus Tolypocladium was separated from the Verticillium complex by Barron (3) and Gams (9) to include verticillate species that have conidiogenous cells with inflated bases. Tolypocladium parasiticum produces small quantities of efrapeptin A, a type of toxic peptide unique to the genus Tolypocladium (2) that may be helpful for identification of this genus. The separation of isolates DC116 and DC120 from ex-type strains of $V$. fungicola based on rDNA sequence data suggests that these isolates were misidentified. Further morphological and molecular analyses, including investigations into the production of efrapeptins, are required to determine the true taxonomic status of these isolates.
Perhaps the most interesting feature of these analyses is the sequence relationships of $V$. fungicola var. aleophilum and $V$. fungicola var. fungicola with species of Cordyceps and Paecilomyces, two genera commonly found on insect hosts. The similarity between rDNA sequences of isolates from groups $V$. fungicola var. aleophilum and $V$. fungicola var. fungicola with fungi that parasitize insects suggests that these genera may share a common ancestor that utilized a chitin substrate for growth. It is possible that strains from groups V. fungicola var. aleophilum and V. fungicola var. fungicola are capable of parasitizing insects as secondary hosts. The chitinaceous exoskeleton of sciarids (Lycoriella sp.) and phorids (Megaselia sp.), flies commonly associated with mushroom crops, acting as alternate hosts for these varieties of $V$. fungicola has yet to be explored. If the varieties of $V$. fungicola were capable of parasitizing mushroom-infesting flies associated with mushroom production, our current understanding of the epidemiology of dry bubble disease may be expanded. Additional gene sequences and phylogenetic analyses of other parts of genomes, such as beta-tubulin or elongation factor 1 alpha, of these fungi would be required in order to further examine the genetic relatedness of $V$. fungicola varieties to entomopathogens.

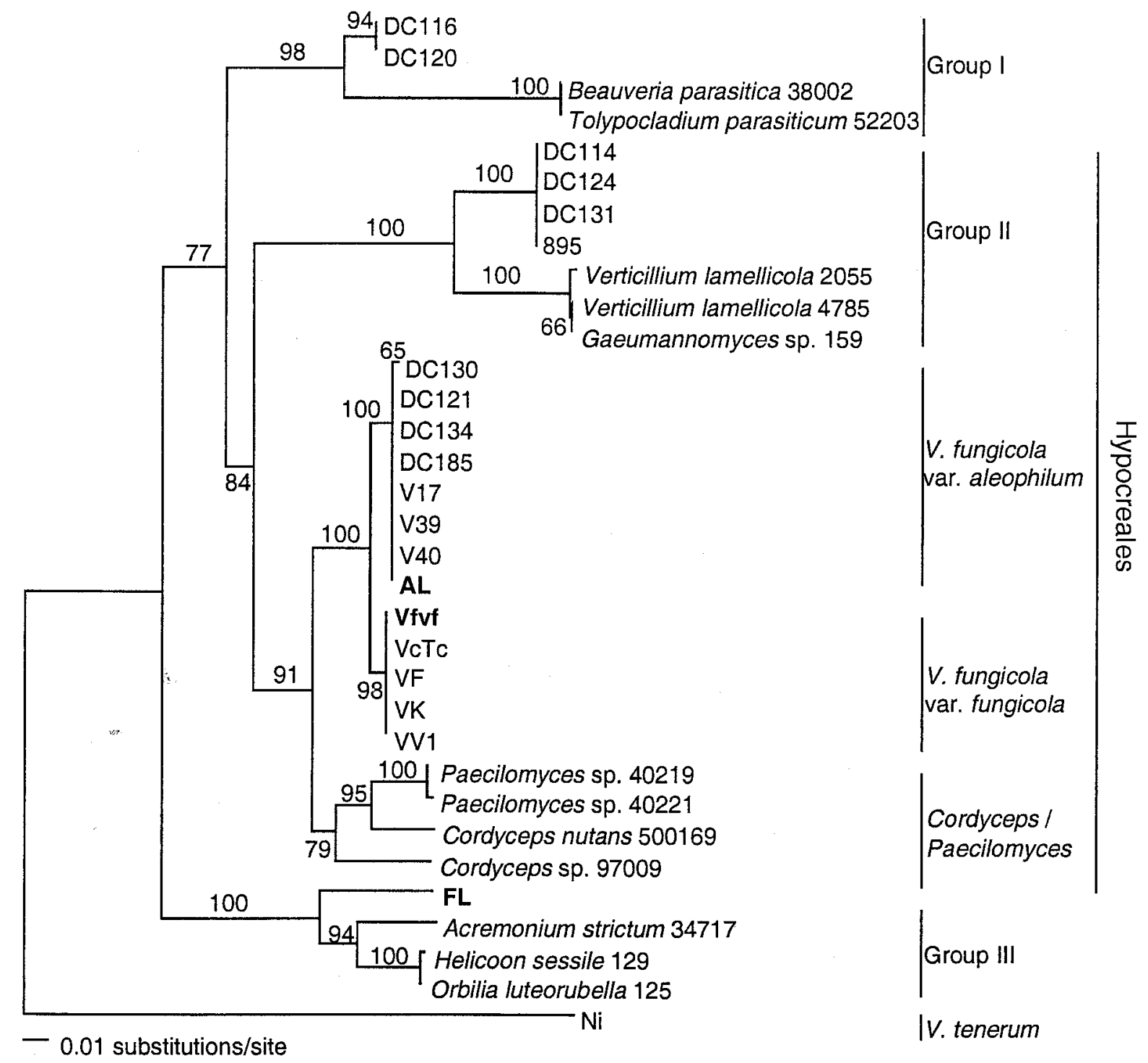

Fig. 4. Relationships among Verticillium isolates and other isolates with sequence matches from NCBI nucleotide sequence databases. Inferences were constructed using the neighbor-joining method with distance analysis calculated with the Kimura two-parameter model. Bootstrap values shown at branches were obtained from 1,000 replications. Vertical bars represent taxonomic groupings. Ex-type strains for varieties of $V$. fungicola are indicated in bold type. 


\section{ACKNOWLEDGMENTS}

We thank C. Fordyce of Longwood Biological Labs (Avondale, PA) for supplying isolates of V. fungicola collected in 1999, and D. Geiser of Pennsylvania State University, for providing invaluable advice concerning the tools and practices of phylogenetic analyses.

\section{LITERATURE CITED}

1. Altschul, S. F., Gish, W., Miller, W., Myers, E. W., and Lipman, D. J. 1990. Basic local alignment search tool. J. Mol. Biol. 215:403-410.

2. Bandani, A. R., Khambay, B. P. S., Faull, J. L., Newton, R., Deadman, M., and Butt, T. M. 2000. Production of efrapeptins by Tolypocladium species and evaluation of their insecticidal and antimicrobial properties. Mycol. Res. 104:537-544.

3. Barron, G. L. 1980. Fungal parasites of rotifers: A new Tolypocladium with underwater conidiation. Can. J. Bot. 58:439-442.

4. Bidochka, M. J., St. Leger, R. J., Stuart, A., and Gowanlock, K. 1999. Nuclear rDNA phylogeny in the fungal genus Verticillium and its relationship to insect and plant virulence, extracellular proteases and carbohydrases. Microbiology (UK) 145:955-963.

5. Bonnen, A. M., and Hopkins, C. 1997. Fungicide resistance and population variation in Verticillium fungicola, a pathogen of the button mushroom, Agaricus bisporus. Mycol. Res. 101:89-96.

6. Castle, A., Speranzini, D., Rghei, N., Alm, G., Rinker, D., and Bissett, J. 1998. Morphological and molecular identification of Trichoderma isolates on North American mushroom farms. Appl. Environ. Microbiol. 64:133-137.

7. Chen, X., Romaine, C. P., Ospina-Giraldo, M. D., and Royse, D. J. 1999. A polymerase chain reaction-based test for the identification of Trichoderma harzianum biotypes 2 and 4, responsible for the worldwide green mold epidemic in cultivated Agaricus bisporus. Appl. Microbiol. Biotech. 52:246-250.

8. Felsenstein, J. 1985. Confidence limits on phylogenies: An approach using the bootstrap. Evolution 39:783-791.

9. Gams, W. 1971. Tolypocladium eine Hyphomyceten gattung mit Geschwollenen Phialiden. Persoonia 6:185-191.

10. Gams, W. 1995. How natural should anamorph genera be? Can. J. Bot. 73:S747-S753

11. Gams, W., and Van Zaayen, A. 1982. Contribution to the taxonomy and pathogenicity of fungicolous Verticillium species I. Taxonomy. Neth. J. Plant Pathol. 88:57-78.

12. Higgins, D. G., Bleasby, A. J., and Fuchs, R. 1991. CLUSTAL W: Improved software for multiple sequence alignment. Cabios 8:189-191.

13. Jukes, T. H., and Cantor, C. R. 1969. Evolution of protein molecules.
Pages 22-132 in: Mammalian Protein Metabolism. H. N. Munro, ed. Academic Press, New York.

14. Kimura, M. 1980. A simple model for estimating evolutionary rates of base substitutions through comparative studies of nucleotide sequences. J. Mol. Evol. 16:111-120.

15. Lambert, D. H. 1973. Population studies of Verticillium species associated with Agaricus bisporus (Lange) Imbach. M.S. thesis. The Pennsylvania State University, University Park.

16. Moore, R. K., and Wuest, P. J. 1972. The effect of aerated steam treatment of mushroom casing on recolonization by Verticillium malthousei. (Abstr.) Phytopathology 62:498.

17. Moore, R. K., and Wuest, P. J. 1973. Occurrence and severity of Verticillium disease of mushrooms produced on casing (soil) treated with aerated steam. Phytopathology 63:1368-1374.

18. Muthumeenakshi, S., Mills, P. R., Brown, A. E., and Seaby, D. A. 1994. Intraspecific molecular variation among Trichoderma harzianum isolates colonizing mushroom compost in the British Isles. Microbiology 140:769-777.

19. Ospina-Giraldo, M. D., Royse, D. J., Thon, M. R., Chen, X., and Romaine, C. P. 1998. Phylogenetic relationships of Trichoderma harzianum causing mushroom green mold in Europe and North America to other species of Trichoderma from world-wide sources. Mycologia 90:76-81.

20. Rinker, D. L. 1994. Trichoderma green mold: A seminar by Dr. Donald Betterly, Monterey Labs. Mushroom News 42:20-23.

21. Saitou, N., and Nei, M. 1987. The neighbor-joining method: A new method for constructing phylogenetic trees. Mol. Bio. Evol. 4:406425

22. Schisler, L. C., and Wuest, P. J. 1982. Selecting, manipulating, and treating mushroom casing. Pages 55-60 in: Penn State Handbook for Commercial Mushroom Growers. P. J. Wuest and D. J. Bengston, eds. The Pennsylvania State University, University Park.

23. Thompson, J., Higgins, D., and Gibson, T. 1994. CLUSTAL W: Improving the sensitivity of progressive multiple sequence alignment through sequence weighting, position-specific gap penalties and weight matrix choice. Nucleic Acids Res. 22:4673-4680.

24. Van Zaayen, A., and Gams, W. 1982. Contribution to the taxonomy and pathogenicity of fungicolous Verticillium species. II. Pathogenicity. Neth. J. Plant Pathol. 88:143-154.

25. Ward, E., and Bateman, G. L. 1999. Comparison of Gaemannomycesand Phialophora-like fungal pathogens from maize and other plants using DNA methods. New Phytol. 141:323-331.

26. White, T., Bruns, T., Lee, S., and Taylor, J. 1990. Amplification and direct sequencing of fungal ribosomal RNA genes for phylogenetics. Pages 315-322 in: PCR Protocols. M. Innis, D. Gelfand, J. Sninsky, and T. White, eds. Academic Press, San Diego. 